
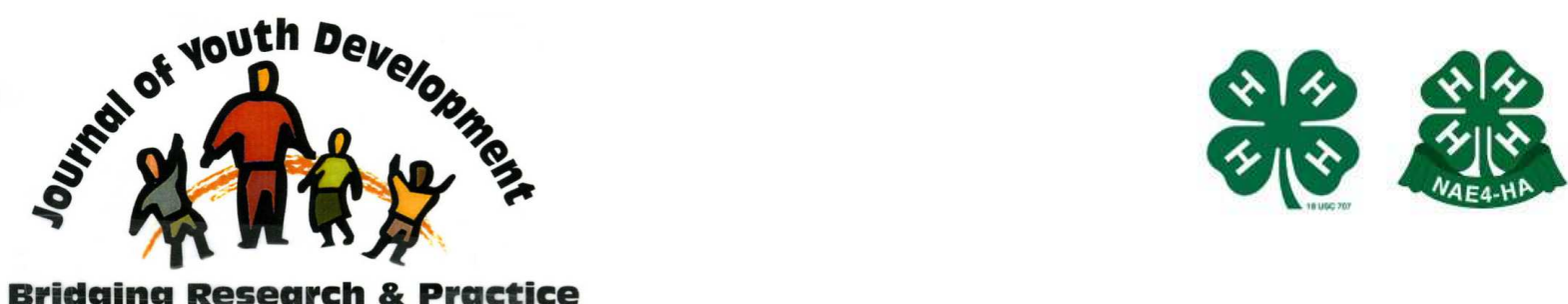

Bridging Research \& Practice

\title{
Community-Based After-School Inclusive Programs for Low-Income Minority Youth and Their Families: the Disability Specialist Approach
}

\author{
Donald G. Unger \\ Department of Individual \& Family Studies \\ University of Delaware \\ unger@udel.edu \\ Tara Woolfolk \\ Department of Individual \& Family Studies \\ University of Delaware \\ Vanessa Harper \\ Center for Disabilities Studies \\ University of Delaware \\ Teresita Cuevas \\ Center for Disabilities Studies \\ University of Delaware
}




\title{
JOURNAL OF YOUTH DEVELOPMENT \\ bridging research and practice

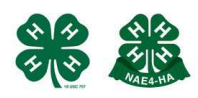

\section{Community-Based After-School Inclusive Programs for Low-Income Minority Youth and Their Families: the Disability Specialist Approach}

\author{
Donald G. Unger, Tara Woolfolk, Vanessa Harper, and Teresita Cuevas \\ University of Delaware
}

\begin{abstract}
Intervention for helping community based after-school programs become more responsive to youth with disabilities and their families is presented in this manuscript. The Disability Specialist intervention utilized a variety of approaches, including: a) increasing awareness of disabilities and services by providing learning opportunity sessions for families and staff, and outreach activities to youth through interactive theater; b) developing in house "disability specialists" to offer ongoing leadership and technical expertise for after-school programs and their community centers; c) developing a network of technical consultants in order to connect families and after-school programs to specialized community resources; d) providing financial assistance to enable community center staff to allocate time to outreach activities; and e) providing families with support in educational advocacy efforts by partnering with a local parent mentoring program. The success of the project depended upon building partnerships with families, community centers, human service agencies, schools, and local funding sources.
\end{abstract}

\section{Introduction}

Quality after-school programs are increasingly recognized as beneficial to youth development (Halpern, 1999). After-school programs located near a youth's residence may be especially important in low-income, minority communities when neighborhoods have insufficient recreational, pro-social, and educational opportunities. For youth with disabilities, an afterschool program can be a salient source of emotional, social, and academic support (Fink, 2000). With the proper resources, an after-school program can also help caregivers recognize and 
understand their children's disabilities, deal with the stressors associated with parenting a child with a disability, and learn how to advocate within schools for appropriate supports and accommodations for their youth with disabilities.

Community based after-school programs provided in low-income communities are often challenged by limited funding and resources (Halpern, 1999). Their personnel typically are highly dedicated, but they may have insufficient training in developmental and educational concerns of children and youth with disabilities (Scholl, Smith, \& Davison, 2005). Staff skills in effectively communicating with parents and school personnel may also be under-developed. When youth with disabilities attend after-school programs, this can therefore add an additional demand on community based after-school programs. After-school staff may become frustrated, youth with disabilities may not feel welcome or supported, and families may become disengaged with the program and the potential helpful resources it could offer.

This article describes a demonstration project that was designed to build community support systems to help families and after-school programs meet the needs of all youth, including both those with and without disabilities.

\section{Identified Needs Focused upon by the Disability Specialist Program}

The Disability Specialist program was developed in response to the unmet needs of urban, minority children and youth with disabilities and their families in the Mid-Atlantic region of the United States. These needs were identified through a community needs assessment conducted during 2001-2002. Focused interviews with key informants (directors of nonprofit and state human service agencies, community leaders) were conducted along with interviews of a diverse group of families, including those from African American and Latino backgrounds in underserved, low-income communities. Additional information was gathered from prior assessments completed by local state departments of education, mental health, and public health.

One primary finding of the needs assessment was that families of youth with disabilities did not believe that after-school programs and "generic" human service agencies (i.e., agencies not exclusively serving those with disabilities) were adequately prepared to meet the needs of their children and/or were not aware of the needs of families with youth with disabilities. In particular, parents felt that program personnel lacked the skills and knowledge for handling challenging behaviors associated with children's disabilities. Parents and staff frequently mentioned that when youth with disabilities did get enrolled in programs, they were often "kicked out" of the programs due to the "disruptiveness" of their behaviors. After-school community programs and generic human service agencies were also often overwhelmed with the prospect of understanding and working with the service delivery system for children with disabilities because the system was so fragmented and difficult to navigate. For instance, in Delaware, services for individuals and family members were offered across three departments and eight divisions.

A second finding was that families with children and youth with disabilities wanted their children to attend inclusive after-school care programs but they were rarely available. In addition, while having after school programs in their communities was important, parents also wanted high quality care. However, after-school programs were most often staffed by paraprofessionals, part time employees, and young adults who had limited training. Frequently absent was an 
understanding of learning disabilities, the educational rights of children, and accommodations that could help children succeed. Lack of information was also evidenced by inaccurate beliefs about disabilities. Many staff thought only of disabilities in terms of physical mobility limitations, or severe mental retardation or illness. Some staff questioned the wisdom of inclusion. Even with both legislative and empirical support for the inclusion of children with disabilities into community based child care programs (Moon, 1994; Moon, et al., 1994), many were reluctant. Some believed that after-school programs did not have the financial resources or the staff to provide services to children with disabilities. Similarly, Scholl, Smith, \& Davison (2005) found managers at community programs to be reluctant to allocate funds, and adjust staffing levels and activities so that children with disabilities could be included.

A third finding of the local needs assessment was that low-income parents typically had the desire, but not the information and support in order to be effective advocates for their children. Parents, for instance, expressed frustration at being unable to establish effective partnerships with schools, and believed that many youth were not being adequately served by the local public school system. Also, families were looking for culturally competent support provided by persons from their communities, who worked in local community settings, and had a mature understanding of the culture of their communities. Historically, many low-income African American parents have expressed concerns about their children being misdiagnosed, provided with inappropriate mental health services, and segregated into special education programs (Harry, 1992).

Based upon these results, we concluded that after-school program staff needed to understand and be equipped to help children with many different types of abilities and disabilities. With adequate training, staff could offer more diversity and choices in programming to meet a wider range of children's needs. Moreover, the staff of such programs would know how to collaborate more effectively with schools and other social service organizations that had specialized expertise and resources to provide services for children and youth with and without disabilities. Halpern (1999), for instance, in his review of after-school programs for low-income children, concluded that a primary method for strengthening programs was to develop a network of programs and stakeholders that could provide on-going training and technical assistance. Staff could learn to provide these services in a culturally competent manner, for example, by acknowledging minority issues and barriers to services, and learning effective ways to navigate service delivery systems.

Similarly, parents as well as staff needed opportunities to learn about disabilities and the services that could be made available for their children. Parents also needed a support system to enable them to be effective advocates for their children in school systems.

Lastly, we concluded that parents, youth, and staff needed assistance understanding the value of inclusion and creating a community atmosphere of acceptance. Through inclusion, children without disabilities can learn to value diversity and the strengths that each child brings to a program (Peck, Staub, Gallucci, \& Schwartz, 2004). For children with disabilities, some of the benefits of inclusive programs may include fewer segregation effects, more appropriate peer models, increased social skills, and greater opportunities to develop interests, skills, and friendships (Downing, \& Eichinger, 2002). 


\section{The Disability Specialist Intervention}

The Disability Specialist Intervention was a community-family-school based demonstration project designed to provide assistance and support to community-based urban after-school programs so they could reach all children, with and without disabilities. The program had four components.

- First, increased awareness and understanding about disabilities was accomplished through outreach to families, with and without family members with disabilities. Afterschool and human service staff at the community centers were also included in these disability awareness activities.

- Second, outreach to youth to increase awareness of disabilities occurred, in part, through an arts and theater project.

- Third, staff working in community centers in low-income communities were recruited and trained to become "Disability Specialists."

- Fourth, child advocacy and assistance in obtaining educational resources for youth with disabilities was accomplished through collaborations with parent mentors who were volunteers of a local Association for the Rights of Citizens [ARC] program in Delaware.

This project received funding from a grant from the Administration on Developmental Disabilities, Department of Health and Human Services, and the Delaware Developmental Disabilities Council.

\section{Outreach to Families and Staff}

Families of youth with and without disabilities were initially contacted to attend "Learning Opportunity" sessions. They were reached through flyers at local community centers, churches and agencies, as well as through invitations at community meetings and at informal meetings with parents. The Learning Opportunity sessions focused on understanding children with disabilities and their families, as well as supporting and empowering all families. The sessions were designed to increase understanding of disability and related family support issues, and awareness of community resources available to address youth and family support needs.

Through these family sessions, parents' questions, myths, and concerns were addressed. Goals included:

- increasing their knowledge about developmental and learning disabilities;

- identifying youth and family needs;

- locating and using appropriate educational, community, and health services;

- differentiating between passive, aggressive and assertive behaviors when advocating for a family member.

Attendees also had opportunities to practice positive vocabulary and behaviors that help to bring dignity and respect to people with disabilities by:

- identifying stereotypes about people with disabilities;

- rephrasing and updating terms traditionally used to refer to individuals with disabilities;

- demonstrating different ways to interact effectively with people who have disabilities. 
After-school and other community center staff also participated in Learning Opportunity sessions. In addition to the goals included in the family sessions, staff were expected to learn about specific types of disabilities, and to learn ways to help family members prepare themselves to more effectively seek services and advocate for needed services.

An important feature of the implementation of all Learning Opportunity sessions was that they were co-lead with at least one leader being a family member with a disability. Parents with family members with a disability were recruited prior to the delivery of the Learning Opportunity Sessions, and received a separate training.

Lastly, a website was created for staff and family members that included information about specific disabilities, parenting and caregiver tips on handling challenging behaviors associated with specific disabilities, information about possible services for individuals with specific disabilities, state and federal laws and policies regulating services and parental rights, and links to local community resources. The goal was to help staff and family members navigate the sometimes overwhelming amount of information available on the internet in a user-friendly manner. The information included on the website, other than links to agencies, was selected from sources in the public domain and not copyrighted (mostly from government documents and disability advocacy organizations). Sources were carefully reviewed, selected for their content and user-friendly presentation, and then converted into PDF documents for inclusion on the website (each document maintained its original formatting, and included complete citation for the original information/website location). The choice to include PDF documents rather than just links to other websites was made because of the changing content and continual reorganization of information on so many websites, and our inability to dedicate funds to update our website to keep up with such changes.

\section{Outreach to Youth: Community Arts and Theater Component}

It was important to reach out to all youth participating in the after-school and community center programs, both those with and without disabilities. An art and theater project was developed to increase awareness of disabilities and inclusion. Youth with disabilities were recruited from community centers and a local vocational/technical high school to design and then present the project to other youth. An interactive theatre approach was chosen because it encouraged audience members with and without disabilities to become part of the presentation, to build upon the strengths and input of youth, and use concerns identified by the youth to direct the course and outcomes of the project. As a result of the project, youth learned about what a disability was, and what it meant to live with specific disabilities. Moreover, issues of inclusion and exclusion were discussed along with how power dynamics affect society and youth. Youth learned communication skills and expressive techniques without having any prior experience in performing arts. Lastly, techniques for mentoring and working with youth and younger children were discussed so that the presenters would have skills to deal with topics as they arose during the course of presentations. In addition, a handbook was produced for future use by community center and after-school staff which included instructions for creating a youth leadership group, for implementing presentations and involving the audience, and for creating opportunities for future mentoring between youth leaders and younger children (CATP, 2004). 


\section{Recruitment, Training, and Support of Disability Specialists}

Individuals working with youth and families at community centers in low-income, minority communities were identified and recruited. They were expected to participate in a Fellowship training program, and then serve as a "Disability Specialist" for after-school programs and other child and youth programs at their community centers. The Fellowship included training to increase their expertise in disabilities, as well as financial compensation so they could allocate more of their professional time to family and school outreach, and to assessing child and family needs, providing information, referral and follow-up, and helping promote self-advocacy.

Seven Disability Specialists participated in a weekly Fellowship Training Program over approximately 5 months. The topics of the trainings are listed in Table 1.

\section{Table 1}

Disability Specialist training topics

\begin{tabular}{|l|}
\hline \multicolumn{1}{|c|}{ Topics } \\
\hline Introduction \& Overview \\
\hline Conflict Resolution \& Mediation Services for IEP \\
\hline Laws \& Rights: IDEA Basic Rights \\
\hline Special Education Services: Developing a SMART IEP \\
\hline IEPs \& Alternate Assessment: IEPs \& DSTP Process \\
\hline Transitions and Permanency Planning: Maps \& Paths \\
\hline Laws \& Rights: ADA \& Section 504 \\
\hline Mental Health Issues Part 1: Childhood \\
\hline Mental Health Issues Part 2: Adolescence \\
\hline Managing Challenging Behaviors: Positive Behavioral Support Part 1 \\
\hline Managing Challenging Behaviors: Positive Behavioral Support Part 2 \\
\hline Disabilities, Learning Differences \& Instruction \\
\hline School Age Children with Disabilities \& Their Families: An Integrated Approach \\
\hline Inclusion \& Barriers to Inclusion \\
\hline Panel of Delaware Service Providers: Interactive Session \\
\hline Transition Services for Young Adults \\
\hline Assistive Technology \\
\hline Advocacy \& Lifespan Respite Care \\
\hline Family Needs, Supports \& Disabilities \\
\hline Professionalism \\
\hline GRADUATION/WRAP UP \\
\hline
\end{tabular}


A unique feature of the training was that discussions included a focus on collaborating with schools and families. For example, by completion of their Fellowship, Disability Specialists were expected to learn about children's rights and opportunities in special education, and to identify techniques that parents could use to enhance collaboration in the Individualized Education Plan (IEP) process. In addition, Disability Specialists learned to:
a) identify \& demonstrate strategies to achieve effective collaboration between family members and professionals,
b) identify strategies for developing an equal partnership between family members and professionals,
c) build understanding of family experiences and needs,
d) identify barriers in family situations,
e) identify family strengths,
f) identify and understand services in the community that were available to address individual and family needs, and to
g) advocate for appropriate and inclusive services for individuals with disabilities within their communities.

An important feature of the Disability Specialists program was the availability of ongoing technical assistance and mutual support to the Disability Specialists. A member of the intervention team provided on-site consultation and support between training sessions. This enhanced Specialists' skills for providing case management, and provided the needed support and encouragement when working with challenging youth and their families. An additional significant feature of the Disability Specialist program was for the Specialists to build a resource network among themselves through which they received mutual support and peer guidance. Continued, ongoing technical and emotional support after the training was also accomplished through monthly meetings, networking between Disability Specialists, and assistance from the project's staff.

Lastly, a key feature throughout the Disability Specialist training was that representatives and providers from local and state agencies offering services to individuals with disabilities were invited presenters. This offered the Disability Specialists opportunities to meet agency representatives, and to begin establishing themselves as known and legitimate entities to the agencies. These relationships and contacts served as important resources for the Disability Specialists as they worked with youth and their families and referred them for needed services.

\section{Family and School Support}

The program collaborated with a Parent Mentor Program, a local community program providing a wide range of services to individuals with disabilities, i.e., The ARC of Delaware. Parent Mentors were trained to help parents advocate for children's educational needs and negotiate school systems and issues, attend IEP and related school meetings with caregivers, and make referrals to community agencies. Parent Mentors were parents of children with cognitive and developmental disabilities who believed in inclusive education. They were trained in special education laws and regulations and conflict resolution, and were supervised by The ARC of Delaware. 
The Parent Mentors were a critical component of the Disability Specialist program because they provided the "school connection" for the families and Disability Specialists in community centers. Over the course of this demonstration project, many parents continually expressed their frustrations in attempting to acquire the necessary educational supports so that their children's educational needs could be successfully met. In contrast, another frequent issue was the lack of parental awareness and understanding of the specific educational needs of their children. Related to this was the lack of communication between the after-school programs in the community centers and the educational professionals in the children's schools regarding children's IEP's, educational needs, and strategies to address these needs. The Parent Mentors were primarily responsible for supporting parents' involvement in their children's schools. They provided information about local, statewide, and national resources, and made referrals when appropriate. They provided emotional support and expertise as a parent who also had a child with a disability and/or special need. When requested, they would accompany parents to school meetings. The Mentors were expected to follow four guiding principles:

- Foster self-competence in families and children

- Respect individual and family choices

- Build upon family strengths, promote resilience, and respect cultural diversity

- Involve families in all aspects of services

Disability Specialists needed Parent Mentors as partners in providing support to families because collaborating with teachers and school professionals is a time consuming and specialized activity requiring the dedication of human resources far beyond what after-school programs were able to allocate.

\section{Program Evaluation}

A formative approach was used to evaluate the Disability Specialist program. The evaluation focused on providing information that would be helpful in documenting, implementing, and refining the project. A database using Filemaker Pro was developed to track the attendance of family members and staff at Learning Opportunity Sessions, along with their satisfaction with the meetings. Over the course of the project (10/2002-6/2004), 368 family members attended the Learning Opportunity sessions, which lasted an average of 1.97 hours (ranging in length from 1-3 hours). The typical group size was approximately 6.9 participants made up of mostly mothers (83\%) and some fathers (17\%). The majority of participants were African American (54.3\%); others were White $(30.7 \%)$ and Latino $(11.1 \%)$ (3.8\% of family members declined to identify their race/ethnicity).

When Learning Opportunity sessions were held for staff, the majority of participants were African-American (73.1\%). The remainder were either White $(20 \%)$ or Latino $(6.9 \%)$. The sessions lasted approximately 1.54 hours, with typically 7.9 staff members attending, who were predominately female $(78 \%)$.

Satisfaction with the Learning Opportunity sessions was evaluated using five questions with a four point Likert-style rating scale (e.g. Was the information presented: (1) a good refresher?...(4) new to me?). These were followed by 6 incomplete sentences requiring openended responses (e.g. "I still have questions about..."). Responses were then entered into a Filemaker Pro database. Overall, families (90\%) and staff members (83\%) were very satisfied with the sessions. 
During the Disability Specialist training, a similar Learning Opportunity Evaluation Form was completed to provide feedback on each day's topical presentation. To document the activities of the Disability Specialists, each Disability Specialist completed Activity Logs during and after they received training. On each Activity Log, Specialists indicated the specific focus of their work from a list provided on the Log (see Figure 1). Space was also provided on Activity Logs so narratives could be included about a) activity details, b) next steps, and c) help needed. Responses were entered on a monthly basis in a Filemaker Pro database that was then used to create timely reports on a) individual disability specialist's activities, b) monthly totals, c) "next steps" underway by specialists, and d) any help that specialists anticipated that they would need to carry out their activities.

Figure 1

Disability Specialist Activity Log

\section{Disability Specialist Activity Log}

\begin{tabular}{|c|c|}
\hline \# Hours & Name \\
\hline Activity - choose only one & Program: \\
\hline \multicolumn{2}{|c|}{$\begin{array}{ll}\text { O 1. Outreach to individuals with disabilities } & \text { O 9. Meet with Family Support staff } \\
\text { O 2. Referrals to / followup with community agencies } & \text { O 10. Caregiver counseling/advocacy } \\
\text { O 3. Referrals to / followup with schools } & \text { O 11. Seek info re: availability, eligibility for services } \\
\text { O 4. Followup with child, adult or family } & \text { O 12. Education/Disability awareness for human service providers } \\
\text { O 5. Support, consult with staff at center } & \text { O 13. Other } \\
\text { O6. Organize, host meetings with families or individuals } & \\
\text { O 7. Attend training } & \\
\text { O 8. Read, review training or other material } & \end{array}$} \\
\hline \multicolumn{2}{|l|}{ Activity Details and New Contacts } \\
\hline Next Step(s) & Help Needed \\
\hline & \\
\hline & \\
\hline & \\
\hline & \\
\hline
\end{tabular}

The types of activities carried out by Disability Specialists included:

- outreach to individuals with disabilities (24\%),

- follow-up with a child, adult, or family $(18 \%)$,

- support or consultation with staff at the Specialist's center (18\%), referrals and followup regarding referrals $(13 \%)$,

- education/disability awareness with human service providers at other community agencies $(10 \%)$,

- caregiver counseling and advocacy (8\%), 
- seeking information regarding availability and eligibility information for disability services (7\%), and

- hosting group meetings with families or individuals (2\%).

Parent Mentor school visits with parents, help provided to parents regarding the Individualized Education Plan/Special Education process, parental rights, and available services for youth with disabilities, were monitored by a supervisor at the Parent Mentor host organization, The ARC of Delaware.

\section{Replication}

There were several important lessons learned from the Disability Specialist project that should help others desiring to replicate the project. These include:

- Disability Specialists need to have a pre-established "presence" in their communities. Our Specialists were already trusted by many families in the community, embraced being involved in outreach activities with youth and families, and had a passion for helping disenfranchised youth with and without disabilities. By virtue of the project's association with key community people, youth and families felt welcome and able to access services in an atmosphere of credibility and reduced stigmatization.

- Management in community centers must "buy into" the importance of their centers serving youth with disabilities. Through numerous disability awareness discussions, the Executive Directors of the participating community centers came to believe that the inclusion of youth with disabilities fit with their organizations' missions, and saw the benefit to families and their communities of making commitments of agency resources. When Directors did not see the benefits outweighing the costs, they did not agree to participate. Scholl, Smith, and Davison (2005) similarly note that managers and supervisors in community centers need to not only see inclusion as "desirable" (p. 60), but important enough to allocate resources for their centers to proactively serve youth with disabilities.

- Collaboration is important. Partnerships were developed between families, community centers, human service and state agencies, and schools. Through these collaborations, the Disability Specialists could more effectively serve the diverse needs of families with youth with disabilities.

- Disability Specialists gain confidence and support as a "team." During the training, time was always provided for Disability Specialists to get to know each other, receive support and encouragement from their fellow specialists, and to share information and resources. Disability specialists became a team with mutual concern for each other.

- Disability Specialists need sufficient time and flexibility in their work schedules. In order to meet the needs of youth and their families, Disability Specialists engaged in a wide range of activities, in different settings, and during various times throughout the day that went beyond standard work hours. Their activities as Specialists were only part of their job responsibilities. Without having adequate time and a flexible work schedule, Disability Specialists are at risk for stress and burnout.

- Funding is required to sustain Disability Specialist programs beyond initial "start up" costs. In a time of limited program budgets and increasing needs of low income families (Rank, 2001), after school programs will need financial help to allocate ongoing 
resources in order to have Disability Specialists. For example, the Disability Specialist program was established with federal funding from the Administration on Developmental Disabilities. When the grant period ended, however, community centers wanted to continue the program, but were not able to allocate staff time without outside resources. Continued funding, although at a significantly reduced level, was obtained from a local private foundation and the State Developmental Disabilities Council.

\section{Concluding Comments}

In closing, the success of the program depended upon an approach that worked in synergy with youth, families, communities, and schools. The components of success included:

(a) active collaboration and problem solving with after-school and local community center staff and the families they served,

(b) the allocation of talented, motivated, key staff who worked with families in their local community centers to participate in the Disability Fellowship training,

(c) outreach and education to provide a more inclusive, welcoming environment for all,

(d) Parent Mentors to provide outreach, consultation, and advocacy for parents of youth with disabilities, emphasizing special education and transition services, and collaborating with Disability Specialists,

(e) inclusion of family members with individuals with disabilities in the implementation of the program, and

(f) financial resources so that all components of the Disability Specialist program worked together to support youth and their families.

\section{References}

CATP. (2004). Community arts and theater project program handbook. Newark, DE: Center for Disabilities Studies, University of Delaware.

Downing, J.E., \& Eichinger, J. (2002). Educating students with diverse strengths and needs together: Rationale for inclusion. In J.E. Downing (Ed.), Including students with severe and multiple disabilities in typical classrooms. Baltimore, MD: Paul H. Brookes.

Fink, D.N. (2000). Making a place for kids with disabilities. Westport, CT: Praeger.

Halpern, R. (1999). After school programs for low-income children: Promise and challenges. The Future of Children, 9, 81-95.

Harry, B. (1992). Cultural diversity, families, and the special education system. NY: Teachers College.

Moon, M.S. (Ed.) (1994). Making school and community recreation fun for everyone. Baltimore, MD: Paul H. Brookes.

Moon, M.S., Stiereer, C.L., Brown, P.J., Hart, D., Komissar, C., \& Friedlander, R. (1994). Strategies for successful inclusion in recreation programs. In M.S. Moon (Ed.), Making school and community recreation fun for everyone (pp. 33-62). Baltimore, MD: Brookes. 
Peck, C.A., Staub, D., Gallucci, C., \& Schwartz, I. (2004). Parent perception of the impacts of inclusion on their nondisabled child. Research and Practice for Persons with Severe Disabilities, $29,135-143$.

Rank, M.R. (2001). The effect of poverty on America's families: Assessing our research knowledge. Journal of Family Issues, 22, 882-903.

Scholl, K.G., Dieser, R.B., \& Davison, A. (2005). Together we play: An ecological approach to inclusive recreation. Therapeutic Recreation Journal, 39, 299-311.

Scholl, K.G., Smith, J.G., \& Davison, A. (2005). Agency readiness to provide inclusive recreation and after-school services for children with disabilities. Therapeutic Recreation Journal, 39, 4752.

(C) Copyright of Journal of Youth Development Bridging Research and Practice. Content may not be copied or emailed to multiple sites or posted to a listserv without copyright holder's express written permission. Contact Editor at: patricia.dawson@oregonstate.edu for details. However, users may print, download or email articles for individual use.

ISSN 2325-4009 (Print); ISSN 2325-4017 (Online) 